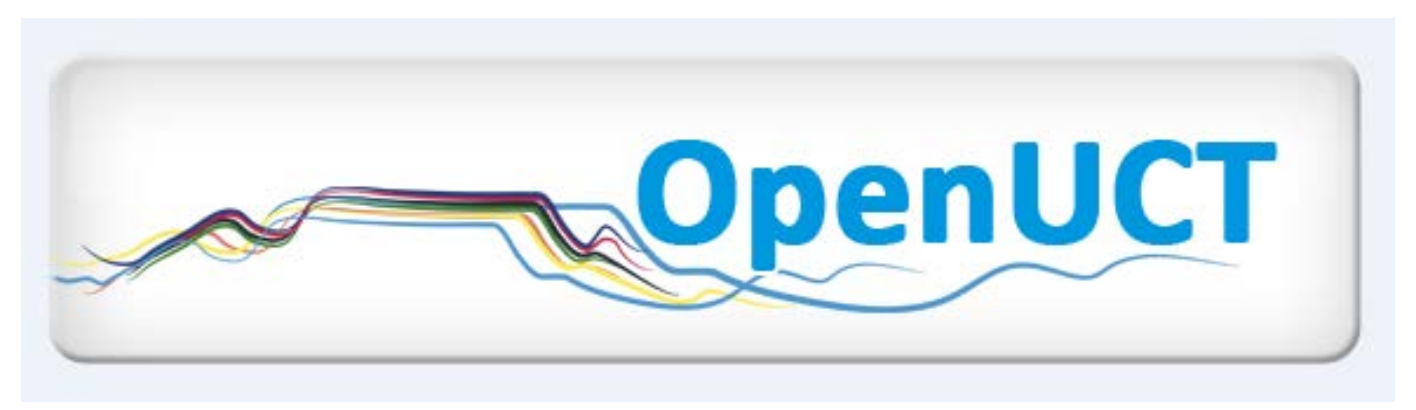

This is the post-print of Shay, S., Ashwin, P. \& Case, J. 2009. A critical engagement with research into higher education. Studies in Higher Education. 34(4): 373-375. DOI: 10.1080/03075070902771879.

It is made available according to the terms of agreement between the author and the journal, and in accordance with UCT's open access policy available: http://www.openuct.uct.ac.za/sites/default/files/UCTOpenAccessPolicy.pdf, for the purposes of research, teaching and private study. 


\section{A critical engagement with research into higher education}

The aim of this special isssue is to promote a critical dialogue about research into higher education with a specific focus on higher education development. Echoing Clegg's argument (in this issue), we argue that higher education development as a profession is coming of age. For an emerging field of practice, it seems appropriate that we critically examine the knowledge which informs these practices and that we interrogate the theoretical frames of reference and methodological approaches which have shaped what we know and how we come to know.

The papers in this special issue are coupled around four broad areas of research in higher education: student learning, academic development, knowledge and curriculum and institutional change. Each couple consists of a 'lead' paper and a 'response' paper, all of which emerged from the Higher Education Close Up 4 (HECU 4) Conference held in Cape Town, South Africa in June 2008. With respect to each of the areas, the 'lead' papers were intentionally selected to raise questions about what is currently known in each of their areas. They aim to provoke in a number of different ways. With respect to research on student learning, Haggis invites us as a community of scholars to take a historical view of what we have published and ask ourselves probing questions about what has been privileged and why. We examine the epistemic alliances we have forged, asking ourselves why these alliances and not others. We note our preoccupation as a research community with certain questions, and wonder at the exclusion of other more disturbing puzzles. What we know, as both Clegg and Badat remind us, is also profoundly shaped by the contexts, both historical and institutional, in which this knowledge is produced. For example, it is only in the context of recent developments in higher education, Clegg argues, that the 'invention' of academic development, and the knowledge produced about it, makes sense. Questioning what we know also entails acknowledging our blind-spots. Barnett argues that we have neglected 'knowledge', and in so doing our discourses have constructed the 'performative student' at the expense of the student in the process of 'epistemic becoming'.

The response paper with which each of the lead papers is coupled takes up the challenge, as Haggis articulates it, to 'know differently'. The major contribution of these authors is not in their findings per se, which emerge from works-in-progress, but in challenging the too-familiar repertoire of concepts, theoretical frameworks and methodological approaches that are drawn upon to research different aspects of higher education. Exposing the complexity of mundane, often overlooked practices, such as Thesen's exploration of the lecture and Lea and Stierer's investigation of academics' everyday writing, requires pushing familiar theory in new directions. Thesen's rather unusual starting point is in fact to set aside the notion of 'learning' and to focus rather on 'engagement', holding together both students and lecturers as participants. Lea and Stierer seek to recharacterize academics' practices as a 
particular example of more general workplace practices rather than assuming these can only be understood as 'academic practices'. The borrowing of powerful theo- retical and analytical tools from our neighbouring sub-disciplines, as Luckett does in her use of Basil Bernstein and Karl Maton, offers insight into the structuring of curriculum which powerfully influences the teaching and learning experience. Taking up Clegg and Badat's challenge, Kloot puts Pierre Bourdieu's theoretical tools to work to highlight the competing interests in the contested practices of academic development in South African higher education. In her lead paper, Haggis argues that as a community we have focused our efforts on 'attempting to shore up certainties'. In contrast, what characterizes all of these 'response' papers is the willingness to take risks in new and unfamiliar research territory, the outcomes of which are unlikely to be tidy or necessarily useful.

The location of HECU 4 in Cape Town, South Africa - a conference historically held in the UK - adds a further dimension to this special issue in its attempt to generate discussion between researchers working in the UK and South Africa. Given the colonial relationship, there are strong continuities between these different higher education systems which offer a platform for meaningful dialogue. And yet, given their different global positionings (the 'North' and 'South' divide), there are significant discontinuities which may shape research agendas in different ways. In particular, the South African articles are all set against the backdrop of the post-

1994 transformation agenda. While 'transformation' will mean something quite particular given the South African context, the issues raised in these papers are likely to resonate in a wide range of context across the globe.

This preview of the different foci of the papers that make up this special issue leads to what we consider to be the key issues arising out of this collection as a whole. First, we argue that this collection showcases the value of explicitly drawing on theoretical perspectives - for example, the use of Bourdieu, Bernstein and Bakhtin - in order to conceptualize social processes in higher education. This point may seem obvious but it merits underscoring in higher education development research where we would argue that theorization has been generally weak. This is important because it is theories, whether implicit or explicit, that provide a characterization of the social phenomena that are the focus of research and thus play a central role in informing what the objects of research look like.

Second, we argue that it is important to recognize that all theories involve a simplification of the complex social processes that make up higher education (see Ashwin [2009] for an exploration of this issue). Thus, drawing on particular theoretical frameworks involves seeing higher education in terms of particular kinds of social processes and not others. This means that no single perspective can deal with the complexity of these processes. Rather, different theoretical frameworks highlight different aspects of the social processes that make up higher education. In other words, all theoretical frameworks simplify but they simplify in different ways. Reflexivity involves an awareness of which approaches are helpful for addressing which types of questions and the different kinds of simplifications that are attendant on drawing on different theoretical approaches. For example, in his lead paper, Barnett, using a philosophical point of departure, calls for a renewed focus on the ways in which knowledge and curriculum can shape students in higher education. Luckett's response draws on a 
different theoretical lens to Barnett, and thus highlights the kinds of knowledge and knower structures which may be privileged in these curricula, and by inference the identities which they inadvertently constitute for students. These two authors' choice of perspective results in very different lines of inquiry, and yet both offer insights for better understanding the complexity of the social processes.

Third, the notion that different theoretical approaches offer different ways of understanding social processes is important in order to counter a tendency that we would argue appears frequently in critiques of higher education development research. This is the tendency not to recognize the value of what different theories, whether 'mainstream' or 'alternative', have to offer. This can create a situation where one way of conceptualizing is reified and others discarded rather than accepting that different ways of characterizing higher education processes highlight different aspects of these processes. Thus it is not about new theories consuming the old, it is rather about having a range of ways of conceptualizing higher education that allows researchers, practitioners, students and policy makers to see in different ways.

We conclude by emphasizing that, as Bourdieu (2000) argues about research more generally, this reflexivity needs to be a collective activity of the field of research into higher education rather than something that can be achieved by single researchers, or groups of researchers, in single research projects. Rather, the relation between theory and methodology in higher education research is something that needs to be the subject of an ongoing, reflexive discussion within the higher education development research community as a whole. It is to such a discussion that we hope this special issue will make a contribution.

\section{References}

Ashwin, P. 2009. Analysing teaching-learning interactions in higher education: Accounting for structure and agency. London: Continuum.

Bourdieu, P. 2000. Pascalian meditations. Trans. R. Nice. Cambridge: Polity Press

Suellen Shay Centre for Higher Education Development, University of Cape Town, Hlanganani Building, 36 North Lane, Private Bag, Rondebosch 7701, South Africa suellen.shay@uct.ac.za

Paul Ashwin

Lancaster University, UK

Jennifer Case

University of Cape Town, South Africa 